\title{
Students in sight: Using mobile eye-tracking to investigate mathematics teachers' gaze behaviour during task instruction- giving
}

\section{Olli Maatta ${ }^{1}$, Nora McIntyre², Jussi Palomäki ${ }^{1}$, Markku S. Hannula ${ }^{1}$, Patrik Scheinin $^{1}$ \& Petri Ihantola ${ }^{1}$}

${ }^{1}$ Department of Education, University of Helsinki, Finland

${ }^{2}$ University of Southampton, United Kingdom

\begin{abstract}
Mobile eye-tracking research has provided evidence both on teachers' visual attention in relation to their intentions and on teachers' student-centred gaze patterns. However, the importance of a teacher's eye-movements when giving instructions is unexplored. In this study we used mobile eye-tracking to investigate six teachers' gaze patterns when they are giving task instructions for a geometry problem in four different phases of a mathematical problem-solving lesson. We analysed the teachers' eye-tracking data, their verbal data, and classroom video recordings. Our paper brings forth a novel interpretative lens for teacher's pedagogical intentions communicated by gaze during teacher-led moments such as when introducing new tasks, reorganizing the social structures of students for collaboration, and lesson wrap-ups. A change in the students' task changes teachers' gaze patterns, which may indicate a change in teacher's pedagogical intention. We found that teachers gazed at students throughout the lesson, whereas teachers' focus was at task-related targets during collaborative instruction-giving more than during the introductory and reflective task instructions. Hence, we suggest two previously not detected gaze types: contextualizing gaze for task readiness and collaborative gaze for task focus to contribute to the present discussion on teacher gaze.
\end{abstract}

Keywords: Mobile eye-tracking; Eye-movement; Mathematical problem-solving; Teacher gaze; Intention.

Corresponding author: Olli Määttä, Department of Education, University of Helsinki, Finland, email address: olli.maatta@helsinki.fi DOI: https://doi.org/10.14786/flr.v9i4.965 


\section{Introduction}

Every lesson offers a new stage. The teacher's first steps on the scene set the tone for the rest of the play. The way a teacher behaves is strongly related to the teaching-learning environment, classroom dynamics and learning outcomes (Hattie, 2003; van der Want et al., 2015; Van Tartwijk et al., 1998; Witt et al., 2004). Moreover, a teacher's tacit pedagogical knowledge feeds into her responses to rapidly changing and unanticipated classroom moments. This knowledge forms the essence of the teaching practice and enables the teacher's professional actions in the classroom (Toom, 2006). Further, the classroom situation provides memory cues for the teacher about similar situations encountered earlier (Simon, 1992). Thus, teachers' reactions result from dynamic, ever-changing classroom situations that demand a situation-specific expression of teacher tact, defined also as mindful action, teacherly awareness, and "the practical language of the body - it is the language of acting in pedagogical moments" (Van Manen, 1991).

Teachers' tactful behaviors are realized in teacher presence which is achieved via verbal and nonverbal teacher immediacy (Mehrabian, 1970). Immediacy behaviors as eye contact induce experiences of closeness and warmth in other people. Related to teacher presence, Jennings and Greenberg (2009) refer to the constructs of self-awareness and social awareness forming teacher's social and emotional competence in their prosocial classroom model. Socially and emotionally competent teachers are effective classroom managers (Jennings \& Greenberg, 2009). Thus, the multilevel actions of classroom management a teacher engages in to create, support, and facilitate the goals of learning in the classroom (Wolff et al., 2017) requires uninterrupted teacher presence. Especially eye-tracking research has revealed the importance of teacher presence manifested by teacher gaze: expert teachers' gaze direction indicates that students are being focused on, and that they are important (McIntyre et al., 2017; McIntyre et al., 2019).

Visual attention consists of conscious and unconscious gaze behaviour (Tatler et al., 2014). Human eye-movements can assist in providing information for inferring intentions and next actions (Lukander et al., 2017), e.g., the teacher's pedagogical intention in the classroom situation. Humans seem to have an innate tendency to learn by understanding where adults look (Csibra \& Gergely, 2009). This has been interpreted as evidence of interaction between a teacher's visual attention and intentions during student problem-solving (Haataja, Garcia Moreno-Esteva, et al., 2019); or how teachers' gaze patterns differ during communicative (information-giving) and attentional (information-seeking) gaze (McIntyre et al., 2017). However, little evidence exists on teacher gaze behaviour during teacher-led sequences, such as when presenting a new activity, when a change in the social structure of collaborative work is introduced and during lesson wrap-ups. Teacher presence is critical to giving task instructions where the teacher at best orients all students around a new learning task and its different phases.

The present article reports on analyses of six teachers' eye-tracking data when they give similar task instructions on a geometry problem in a real-world classroom setting. We focused on the effect of the introductory (contextualizing the task and preparing students for it), collaborative (organizing the social structure of the activity) and reflective (looking back at the process and its outcome) instructiongiving on teacher gaze patterns. Knowing where to look during different phases of the lesson gives teachers an advantage and yet another tool to promote learning. Our work contributes to existing knowledge by addressing how instructions during different types of learning activities affect teacher gaze, and how gaze patterns may reveal teacher's pedagogical intention.

\subsection{Teacher presence is important for classroom climate}

Teachers attend to the classroom climate by their gaze behaviour. Teachers show their presence by gazing towards students when they listen to them; this increases students' experiences of closeness with the teacher (McIntyre et al., 2017). Also, teachers make conscious and unconscious choices regarding eye-contact based on the prevailing social structures and personal intentions (Tatler \& Land, 2016). 
Previous studies have provided a comprehensive overview of teachers' nonverbal immediacy behaviours, which abridge the physical and psychological distance between the interactants (Mehrabian, 1970). These behaviors include smiling, nods, relaxed body posture, forward leans, movement, gestures, vocal variety, and eye contact in the teaching-learning context (Andersen, 1979; Mehrabian, 1970; Witt et al., 2004). Teacher immediacy influences student motivation, which, in turn, results in increased positive affect towards the teacher and the content studied (Christophel, 1990; Frymier, 1994; McCroskey et al., 1995; Richmond, 1990). Moreover, in the context of studying mathematics, teachers' nonverbal immediacy behaviors increase students' positive affect towards the subject and their perceived learning (McCluskey et al., 2017). Thus, in the scope of our study, teacher presence is the realization of teacher immediacy behaviors, such as teacher gaze.

Related to teacher presence, Kounin (1970) introduces concepts as overlapping and withitness to conceptualize teacher's classroom management behaviours: overlapping meaning teacher's ability to spread attention over different things in the classroom, and withitness comprising teacher awareness of what goes on in class, as if having eyes in the back of the head. Consequently, teachers exert differing classroom management actions and attention when responding to the unanticipated situations happening in the classrooms as opposed to striving to meet the aims of the lesson (Wolff et al., 2017).

Generally, teacher support and warmth in the classroom contributes to healthy learning relationships, and students implicitly adopt similar behaviour among their peers (Gest \& Rodkin, 2011; Hendrickx et al., 2016). Yet, the slightest difference in students' or the teacher's behaviour may disrupt or enhance their attention and responsiveness. The dynamics of the classroom are complex. Real-world settings differ by default from static or laboratory circumstances where for example the movement of informants, their position and number can be controlled. In classroom settings, experienced teachers apply their intuitive skills in deciding when to react or not to react in response to classroom events (Berliner, 2004). Teachers are monitoring their students in a nearly subliminal manner (McIntyre, 2016) by gazing toward students (McIntyre et al., 2017). Flexible gaze, moving from emerging classroom problems quicker but visiting them more often typify the gaze behaviour of experienced teachers (Cortina et al., 2015; van den Bogert et al., 2014).

Gaze plays a pivotal role in social interaction because gaze signals enable understanding others' mental states (Baron-Cohen, 1997; Farroni et al., 2002). Further, Tomasello and Carpenter (2007) discuss shared intentionality as a result of joint attention when interactants are experiencing the same thing at the same time and acknowledging that they are doing this. Gaze following and joint attention create a shared space of psychological common ground enabling a shared goal and action plans to emerge in for example problem-solving activities (Tomasello \& Carpenter, 2007). Thus, we anticipate that the teacher's presence and the pedagogical intentions are manifested in the teacher's gazes at specific task-related targets.

\subsection{Teacher gaze reveals teacher's pedagogical intention}

Intention is characterized as a choice with commitment (Cohen \& Levesque, 1990). To identify a teacher's pedagogical intention, we need to examine teacher gaze, as teacher gaze is one important channel for recognizing task-relevant areas in the teaching context. Yet, vision literature identifying other teacher intentions than attentional and communicative underlying teacher gaze (McIntyre et al., 2017) is scarce. However, it is evident from practical experience that teachers do more than ask questions and talk when they teach.

Accumulated classroom experience makes teachers' visual attention more intentional, and they rely more on top-down mechanisms (tasks influencing the gaze behavior) of perception (Haataja, Garcia Moreno-Esteva, et al., 2019). However, teachers are constantly interpreting the dynamic classroom situation and its visual features by focusing their gaze on targets that are important for successful task execution (Wolff et al., 2016). Thus, teachers' gaze behavior is guided by the bottom-up (stimulus 
driven) mechanisms of perception, the top-down mechanisms of visual attention, and the goal-oriented intrinsic intentions (Tatler \& Land, 2016).

There are two aspects of the teacher's pedagogical intention. First, there is a general strategic aspect, when the teacher aspires to meet the learning goals of the lesson. Second, there is also a more tactical situated aspect, when the teacher is noticing, interpreting, and reacting to the situational changes in the classroom. Van Manen (1991) describes this as teachers being constantly active in the immediate interactive processes that aim at maintaining an authentic presence, and a personal relationship with the students. Thus, the general and situated aspects of a teacher's pedagogical intention are intertwined in the teaching-learning context.

We conceptualize teacher's pedagogical intention in the mathematical collaborative problemsolving context in accordance with Tomasello et al. (2005) where the actor has a goal toward which they choose an intended course of actions. Here, we define the teacher's general goal of the lesson as executing the predefined problem-solving task with their students. Further, the teacher chooses a set of actions (a plan) towards the goal based on teacher skills and knowledge employing their situationspecific professional vision in interpretation of the current situation and the problem-solving task. First, the intention is to accommodate students around a new learning activity; and second, to make the students focus on the problem-solving task. We do acknowledge the difficulty in fully knowing the intentions of others (Johnson et al., 2017). Also, as indicated by Frey and Fisher (2010) much of the instructional moves are part of an internalized decision-making process which teachers are not always able to articulate about. However, we assume that in mathematical problem-solving both the task design and the teacher's plan of implementing the task accord with the educational goals of the situation.

Expert gaze has been shown to be task dependent: a meta-analysis has revealed that experts, compared to novices, focus their gaze for shorter periods of time, but more often on areas relevant to the task instead of non-relevant areas (Gegenfurtner et al., 2011). Teachers' gaze patterns vary depending on what students have previously done, what they are currently doing, and what they are going to do next. Thus, we expect to discover previously unseen features of task-dependent teacher gaze.

\subsection{Teacher's gaze depends on instructional type}

In the following, we are exemplifying the effect of the introductory, collaborative, and reflective instruction-giving on teacher gaze patterns. During introductory instruction-giving, teachers contextualize the task and prepare students for it, whereas collaborative instructions aim at organizing the social structure of the activity, and reflective instructions are given to look back at the process and its outcome.

Human eye-movements are highly task and content specific (Rothkopf et al., 2016). Teacher gaze is likely to differ depending on the task teachers are instructing students to complete (McIntyre et al., 2017). Especially during introductory instruction-giving teacher gaze is crucial in eliciting the feeling of togetherness and placing importance on targets related to learning (McIntyre et al., 2017; Wolff et al., 2016). Further, shared attention is critical when signalling what is important when executing the task. For shared-attention to emerge, students engaged in problem-solving need to be aware of oneanother and to anticipate when future collective action is likely to happen (Shteynberg, 2015). Also, teachers deliberately share attention with their students towards critical learning resources of the task, and teacher presence re-engages students to be involved in the shared attention. As Shteynberg (2015) concludes, co-attending a task implies that people also devote more cognitive resources to that task. In triadic engagement an individual interacts together with a goal-directed agent toward a shared goal (Tomasello et al., 2005).

In the present study we are assuming a novel third component in the referential triangle depending on the teacher gaze type. For contextualising gaze aiming at task readiness, we assume the third component alongside with the teacher and student to be conceptual i.e., the shared goal of starting a new learning task. For collaborative gaze - that aims at task focus - we anticipate the third component 
to consist either of the solution paper, the laptop, the calculator, or students' personal items not directly related to the task.

Especially critical to collaborative instruction-giving, teachers are able to read and interpret gaze direction to promote shared attention (Shteynberg, 2015; Baron-Cohen, 1997). Moreover, research delineating the relation between the importance of the gaze target and gaze frequency (Cortina et al., 2015), student-centeredness and gaze flexibility throughout a lesson (McIntyre, 2016), and the role of teacher's intentions on gaze behaviour when scaffolding students' problem-solving (Haataja, Garcia Moreno-Esteva et al., 2019) resonate with teachers' aim of creating connections in the classroom. According to another study (Haataja, Toivanen et al., 2019) students follow their teacher's gaze and especially the dyadic eye contacts between the teacher and students serve two main aims: First, teachers' eye contact enhances immediacy, creates positive emotions, and prevents task-related frustration. Second, teachers' responses to student-initiated eye contacts promote collaboration within the peer group as well as steer students' attention to task-relevant targets.

Interestingly, an inclination may be that teachers' pedagogical intentions of support go beyond the actual problem-solving phase and teachers convey their intentions already when giving the collaborative task instructions. The affective and cognitive scaffolding categories derived by Van de Pol et al. (2010) align with notions of Polya (1948) who instructs teachers to stir up their students' curiosity and to enhance their desire to solve the problem. Haataja, Garcia Moreno-Esteva et al. (2019) conceptualize teacher-student eye contact through scaffolding categories during collaborative problem solving, whereas the present study embraces the role of teacher gaze when giving instructions during lesson phases that both precede and follow the actual problem-solving activity.

For students to succeed in the problem-solving task both applying a model for mathematical problem-solving in general (Lester, 1989; Polya, 1948), and comprehension monitoring in particular (Schurter, 2002) are emphasised. In Schurter (2002), the last phase of comprehension monitoring consists of teacher prompts such as posing questions of the accuracy of the answer, discussions on whether the answer is reasonable or not, and looking for alternate procedures to find the solution. In our study we expect teachers not only to monitor the comprehension but also to steer student engagement by gazing at problem-solving tools, solution papers, and students' personal belongings during collaborative instruction-giving.

\subsection{A mixed analytic approach in examining teacher gaze}

\subsubsection{Durational and proportional analyses}

Our research focus, how teachers' pedagogical intention during different types of instructiongiving are revealed by gaze, was analysed by aggregated teacher gaze measures comparing mean dwell durations and proportional durations for areas of interest (later AOIs) representing student presence and student engagement. We expanded the view on communicative and attentional gaze (McIntyre et al., 2017) by addressing additional teacher intentions underlying gaze. We labelled the two teacher gaze types for task readiness as contextualizing gaze and for task focus as collaborative gaze. Thus, we expect to capture the role of teacher gaze for task readiness and how task focus is sustained by placing importance in task-relevant areas.

\subsubsection{Qualitative analysis of scanpaths and teacher verbalizations}

Investigations into teacher intention were continued by qualitative analysis. We wanted to explore how the introductory instruction-giving and teachers' intentions account for teacher scanpaths in real world dynamic classrooms, for scanpath analysis see e.g. (Anderson et al., 2015). In teaching contexts, scanpaths have been analysed for differences between expert and novice teachers (McIntyre \& Foulsham, 2018). In this study, analysing teacher scanpaths qualitatively offers an insight into teachers' gaze behaviour critical to classroom management. We wanted to depict in detail how teachers use their gaze for enhancing task readiness when starting a lesson with an introductory task instruction. 
Examining the very beginning of the instruction-giving resulted in qualitative analysis of the first 20 gaze targets for each teacher.

Scanpaths are visualizations of how the eye physically moves through space (Holmqvist \& Andersson, 2017). The seminal work by Noton and Stark (1971) presenting "scanpath theory" argues for the top-down character of eye-movements, especially when viewing a previously seen image. Consequently, the visual attention of a participant is guided by the stored image and the scanpath used to view it. Further, Foulsham and Underwood (2008) tested this notion concluding that greater similarity can be found in scanpaths of the same participant viewing the same image twice than a different participant viewing the same image. Thus, top-down and bottom-up explanations end up with the same prediction for viewing static images (Foulsham \& Underwood, 2008). Drawing from research on real world stimuli and tasks Holmqvist and Andersson (2017) conclude that for example task driven plans are behind our eye-movements. Also, scanpath planning and look-ahead fixations precede the actual behaviour related to the task (Mennie et al., 2007). Moreover, additional research on teacher scanpaths is needed to shed light on expert teacher vision (Kaakinen, 2020).

Verbal data and eye-tracking data can be analysed separately to see if the inferences drawn from both datastreams align (Holmqvist \& Andersson, 2017). In order to make more concrete statements about the cognitive structures underlying teachers' gaze patterns we linked the analysis of verbal and eye-tracking data (Jarodzka et al., 2017). Both types of data, eye-tracking data and verbal data consist of datastreams over time, and they are composed of trackable events (Holmqvist \& Andersson, 2017). The best evidence for teachers starting and ending their gazing at the predefined AOIs of interest is their concurrent verbal data (Ericsson \& Simon, 1980).

By analysing teacher verbalizations together with teachers' scanpaths we aim to recognize two teacher's pedagogical intentions related to the introduction of the problem-solving task, first assuming teachers to accommodate students around a new learning activity; and second, to make the students to focus on the instructional resources (black/whiteboard) by gazing at them and suggesting shared attention. We transcribed the separate recordings of teachers' voices by typewriting them. Then we transferred the transcribed written text to the ELAN annotation program (ELAN, Version 5.3, 2018) as a separate tier and aligned it with the gaze coding onsets.

\subsection{Research questions}

We use eye-tracking to examine whether teacher given instructions affect how much and how long teachers look at certain critical targets. Moreover, we want to delineate the momentary gaze behaviour by analysing teacher scanpaths during the starts of the introductory instruction-giving of all six teachers. We expect teachers' pedagogical intention to change with the students' tasks and this, in turn, changes how teacher presence is expressed as well as how task focus is maintained through gaze.

Thus, we report on teachers' gaze behaviour for aggregated variables named student presence and student engagement in research question $(R Q) 1$ and for detailed variables included in student engagement in $R Q 2$. However, in $R Q 3$ we will also report on teachers' gaze behaviour both for instructional resources as black/whiteboard and for targets that guide teachers' work in the classroom i.e., lesson plans which we call as critical activity targets.

Specifically, $R Q 1$ asks: How do instructional types predict teacher gaze for (a) student presence and (b) student engagement during instructions for problem-solving tasks? As teachers monitor the classroom by their gaze, they create a sense of togetherness and prepare students for the upcoming learning session. By doing this, teachers ensure that students are both opt to listen to the instructions given by the teacher, and ready for a new activity. We expect teachers to strive for Student presence and look more at student faces, bodies, and hands when giving introductory instructions compared with instructions given for collaborative tasks. We anticipate that teachers' gaze behaviour would place more importance on Student engagement during collaborative instruction-giving than during introduction of the task and reflection. We assume that this is done to guide students' attention 
to critical problem-solving tools and simultaneously make it clear to students to keep away from distractions.

Additionally, teachers' gaze behaviour should also reveal teachers' interest in how students use their learning tools (calculators, rulers, laptops etc.) and do not use their distracting objects (headphones, mobile phones) indicated by longer dwells at these targets during collaborative task instructions compared with introductory work instructions. Thus, $R \boldsymbol{Q} 2$ asks: How do instructional types predict teacher gaze for the three gaze targets that Student engagement comprises: (a) solution paper, (b) problem-solving tools and (c) distracting objects? We expected that teachers spend longer looking at student solutions when giving instructions for collaborative work compared with introductory tasks. Moreover, we anticipate teachers to place importance on the solution paper by their visual attention when instructing on the reflective phase of the lesson compared with collaborative task instructions. We think that teachers do this to promote student reflection on their solutions, to encourage students to look for alternate ways to solve the problem and reinforce correct answers by concentrating on the solution.

Finally, $R Q 3$ asks: Do instructional types predict teacher gaze for (a) instructional resources and (b) critical activity target? We expect teachers to spend longer looking at the black/whiteboard (Instructional resources) during introduction and reflection than during collaborative task instructions. Also, teachers' gaze behaviour should reflect their need to reference lesson plans throughout the lesson and thus not yield any differences in the length of dwells toward the teacher desk and teacher notes (Critical Activity Target).

\section{Method}

\subsection{Participants and procedure}

The data were obtained from six mathematics teachers (four females, two males), each teacher giving a 45 min lesson with similar content for different students in five lower secondary schools in Southern Finland. Each class was visited twice, and the data are from the second visit. Teachers were between 30 and 56 years old, $(M=46, S D=10.79)$ and with 3-31 years of teaching experience $(M=13.83$, $\mathrm{SD}=9.50)$. The students in the six classes were all 9 th graders (15-16 yrs). The class size varied between 9 and 19 students (total of 94 students). Schools and teachers alike were selected based on their willingness and voluntariness to take part in eye-tracking research. Additionally, a written consent was obtained from the participating teachers and students. Also, students' parents were informed. The data collection took place in Spring 2017.

All participating teachers were given identical task instructions to be delivered along with the problem-solving lesson. The objective of the problem-solving task was to find out the optimal solution to a geometry problem. The research team set up the eye-tracking glasses that had been calibrated at the end of the first lesson and teachers received written task instructions for the lesson (see Table 1 for the complete lesson plan). The task instructions referred to in this research are presented in Table 2. 
Table 1

The complete lesson plan for mathematical problem-solving

\begin{tabular}{|c|c|c|}
\hline $\begin{array}{l}\text { Phase of the } \\
\text { lesson }\end{array}$ & Student activity & Teacher activity \\
\hline 1 & Preparations & $\begin{array}{l}\text { Teacher informs on the } \\
\text { lesson structure, students } \\
\text { fetch papers and rulers }\end{array}$ \\
\hline 2 & Individual seat-work & $\begin{array}{l}\text { Teacher poses the problem } \\
\text { and gives instructions for } \\
\text { individual work. }\end{array}$ \\
\hline 3 & Pair work & Teacher gives instructions for pair work. \\
\hline 4 & Group work & Teacher gives instructions for group work. \\
\hline 5 & $\begin{array}{l}\text { Individual } \\
\text { presentation }\end{array}$ & $\begin{array}{l}\text { Teacher gives instructions for presenting the solutions } \\
\text { individually. }\end{array}$ \\
\hline 6 & $\begin{array}{l}\text { Whole class } \\
\text { discussion }\end{array}$ & Teacher leads the discussion \\
\hline
\end{tabular}


Table 2

Model instructions for mathematical problem-solving task

\begin{tabular}{|c|c|c|}
\hline $\begin{array}{l}\text { Phase of the } \\
\text { lesson }\end{array}$ & Type of instruction & Model instruction \\
\hline 1 & Introduction & $\begin{array}{l}\text { You have four cities; they lie on } \\
\text { the corners of a square. You } \\
\text { have most likely seen how two } \\
\text { places are connected by cable } \\
\text { or optical fiber. First, work } \\
\text { alone and try to find at least } \\
\text { three different ways how the } \\
\text { cities might be connected. } \\
\text { Think which of these is the } \\
\text { best. }\end{array}$ \\
\hline 2 & $\begin{array}{l}\text { Collaboration (pair } \\
\text { work) }\end{array}$ & $\begin{array}{l}\text { Join to work pairwise and } \\
\text { discuss what is the most } \\
\text { effective way of connecting the } \\
\text { four cities, so that the least } \\
\text { amount of cable is used i.e., so } \\
\text { that the total length of the } \\
\text { connection is as short as } \\
\text { possible }\end{array}$ \\
\hline 3 & $\begin{array}{l}\text { Collaboration (group } \\
\text { work) }\end{array}$ & $\begin{array}{l}\text { Get into groups of four and continue searching for the } \\
\text { best possible solution. }\end{array}$ \\
\hline 4 & Reflection & Now present your best solution on the blackboard, plea \\
\hline
\end{tabular}

Note. The teachers delivered the instructions in their personal style.

\subsection{Collection and Preprocessing of Data}

Our target lessons were recorded by three stationary video cameras capturing the action and verbal communication in the classrooms; one camera followed the teacher; the two other cameras were directed towards students wearing the eye trackers. In addition, the teacher's voice was recorded by clipon microphones. Further, mobile eye-tracking devices recorded teachers' eye-movements. The device resembles a protective eyewear equipped with two eye cameras, a scene camera together with electronics connected to a laptop in a backpack letting the teacher move around in the classroom. The eye-tracking devices together with the algorithms and a software for processing the eye-tracking data with an average accuracy of 1.5 degrees of visual angle were designed at the Finnish Institute of Occupational Health (Lukander et al., 2017). The software records the video frames and produces a video of the scene camera, superimposed with a gaze point. The frame rate of the video camera varies depending on lighting conditions being optimally at $30 \mathrm{fps}$.

In this study we analysed eye-tracking data that was collected when teachers were giving introductory, collaborative, and reflective task instructions for a mathematical problem-solving task. To map the teacher's eye-movement behaviour we defined our main metric as a dwell. Researchers agree 
that dwells do not exist without fixations, yet literature lacks a unison definition of a dwell. Orquin and Holmqvist (2018) define dwells as one or more consecutive fixations in an AOI. The dwell is a visit in an AOI, from entry to exit (Holmqvist et al., 2011). Dwell time in turn is the sum of all fixation durations during a dwell in an AOI. Further, as Holmqvist et al. (2011) point out, dwells are oftentimes more dispersed than fixations, longer than fixations and can only be calculated if the stimulus has been categorised as AOIs. As we were interested in specific predefined targets in the classroom upon which teachers were looking, we coded teachers' gaze tracking data in terms of areas of interest (AOIs). Accordingly, the first author annotated all dwells lasting $\geq 3$ consecutive frames $(120 \mathrm{~ms})$ of gaze on an AOI with ELAN software (ELAN, Version 5.3, 2018) using dwell time as our coding unit. The predefined gaze targets i.e., AOIs that we were interested in, were derived from the dependent variables in our research questions. When coding, the areas of AOIs were defined from the superimposed gaze points in the scene camera video. Gaps between two dwells on the AOIs were signalled as a blink or a technical error (for example, eye-tracker losing the pupil of the other eye) by the eye-tracking device and were not included in the coding. Informed by the research questions of our study, all dwells were manually labelled indicating the gaze targets: student presence (student face, body, hands, or gestures), student engagement (students' solution paper, problem-solving tools, and distracting objects as headphones and mobile phones), instructional resources (black/whiteboard and clock), and critical activity target (teacher notes and teacher desk). The detailed coding scheme is provided in Table A3 in the appendix.

\subsection{Measures and analyses}

Our data consisted of 2108 teacher gaze dwells where the shortest dwell coded was $120 \mathrm{~ms}$ and the longest was $16564 \mathrm{~ms}(\mathrm{Mdn}=292 \mathrm{~ms}, \mathrm{M}=502 \mathrm{~ms}, \mathrm{SD}=789.00)$. On average, each teacher's gaze behaviour comprised 351 dwells $(\mathrm{SD}=168)$. The total coded dwell duration for all participants was 17 minutes and 32 seconds. Errors, blinks, and saccades that were not coded as dwells accounted for 8 minutes and 20 seconds (32\%) of the total gaze behaviour, resulting in the overall duration of 25 minutes and 52 seconds of giving instructions during the six lessons. The dwells were further divided between the gaze targets (see Table A3 in the appendix), and for each teacher dwell target (e.g., student engagement), we calculated the mean dwell duration, as well as the proportional duration (how long a teacher looks at one area of interest relative to the length of dwells to other possible regions.)

Observations of not looking at a specific target (i.e., mean dwell duration $=0$ ) were also included when forming the dependent variables. This is done because not looking at all is a signal of the teacher's decision to target the attention toward didactically more crucial targets. Omission of those observations that indicate not looking would only be justified in cases when the gaze target is not present in the classroom at the time of recording. Thus, the teacher's decision not to look at certain targets is considered as a didactic choice. The durations were non-normally distributed, with skewness of 8.32 ( $\mathrm{SE}=0.053)$ and kurtosis of $113.15(\mathrm{SE}=0.107)$. Aggregating the gaze dwells into seven dependent variables mitigated the skew but did not remove it, in part due to the number of zero-value observations for mean dwell durations. Moreover, there is almost always a positive skew in fixation duration data (Holmqvist et al., 2011), and this produces a similar skewness in dwell data.

Instruction type was used as a categorical independent variable (three levels: introductory, collaborative [collapsed over the phases 2 and 3, see Table 2], and reflective). Our dependent variables included both the mean- and proportional dwell durations of i) student presence and ii) student engagement (RQ 1), iii) solution paper, iv) problem-solving tools and v) distracting objects (RQ 2), vi) instructional resources, and vii) critical activity target (RQ 3). Note that the dwell durations assessed in RQ 1 are composed of the dwell durations of "student presence" (i.e., student presence = student face + body + hands + gestures) and "student engagement" (i.e., student engagement $=$ solution paper + problem-solving tools + distracting objects). For brevity, all the results on mean dwell durations, and a summary of proportional dwell duration results, are presented in the Appendix (Figure A2 and Table A5), while the main text focuses on proportional dwell durations (the results for both variables were 
very similar, but proportional dwell durations account for the uneven number of dwells toward each AOI).

To evaluate Research Questions 1-3 (i.e., do instructional types influence teachers' visual attention?), we used the Friedman test, which is a well-known non-parametric test for comparing three or more groups in repeated measurements. In our study, six teachers gave task instructions for introductory, collaborative, and reflective student work, corresponding to three repeated measurements for each teacher. Post hoc comparisons were done using the Conover-Nemenyi method with BonferroniHolm corrections for multiple comparisons.

Human activities (e.g., teachers giving task instructions) draw on visual information acquired by pointing the high-resolution fovea at the gaze targets from which information is required (Tatler et al., 2014). During the relocations, the eye stops for fixations approximately three times a second (Holmqvist et al., 2011). By investigating teacher scanpaths during the critical lesson phases as when introducing new tasks and reorganizing the social structures for collaboration, we expect to extend the previously discovered features of scanpaths to the crucial teacher-led moments of giving instructions. Real-world eye tracking research on eye-movement patterns and differences between teachers' scanpaths aid understanding of how teachers use gaze to create an optimal learning climate as well as to sustain task focus.

Thus, to complement the quantitative analyses, we examined the scanpaths of all six individual teachers for their first 20 gaze targets when they were giving the introductory task instructions. These findings are interpreted qualitatively. An overview of analyses is summarized in Table 3.

Table 3

The analyses used in this research

\begin{tabular}{|c|c|c|c|c|}
\hline $\begin{array}{l}\text { Research } \\
\text { question/Aim } \\
\text { of the study }\end{array}$ & $\begin{array}{l}\text { Target of } \\
\text { analysis }\end{array}$ & Data source & Coding method & Analytic method \\
\hline RQ1-RQ3 & $\begin{array}{l}\text { proportional } \\
\text { dwell } \\
\text { durations }\end{array}$ & $\begin{array}{l}\text { gaze } \\
\text { recordings }\end{array}$ & $\begin{array}{l}\text { ELAN } \\
\text { annotation }\end{array}$ & $\begin{array}{l}\text { Friedman test } \\
\text { and post-hoc } \\
\text { comparisons }\end{array}$ \\
\hline RQ1-RQ3 & $\begin{array}{l}\text { mean dwell } \\
\text { durations }\end{array}$ & $\begin{array}{l}\text { gaze } \\
\text { recordings }\end{array}$ & $\begin{array}{l}\text { ELAN } \\
\text { annotation }\end{array}$ & $\begin{array}{l}\text { Friedman test } \\
\text { and post-hoc } \\
\text { comparisons }\end{array}$ \\
\hline $\begin{array}{l}\text { teachers' } \\
\text { pedagogical } \\
\text { intention }\end{array}$ & $\begin{array}{l}\text { teacher } \\
\text { scanpaths }\end{array}$ & $\begin{array}{l}\text { classroom } \\
\text { video, } \\
\text { gaze } \\
\text { recordings }\end{array}$ & $\begin{array}{l}\text { selection of the } \\
\text { first } 20 \text { and } 5 \\
\text { AOIs during } \\
\text { introductory } \\
\text { instructions }\end{array}$ & $\begin{array}{l}\text { qualitative } \\
\text { descriptions }\end{array}$ \\
\hline $\begin{array}{l}\text { teachers' } \\
\text { pedagogical } \\
\text { intention }\end{array}$ & $\begin{array}{l}\text { teachers' } \\
\text { verbalizations }\end{array}$ & $\begin{array}{l}\text { classroom } \\
\text { voice } \\
\text { recordings, } \\
\text { gaze } \\
\text { recordings }\end{array}$ & $\begin{array}{l}\text { transcriptions of } \\
\text { teachers' } \\
\text { introductory } \\
\text { instructions }\end{array}$ & $\begin{array}{l}\text { qualitative } \\
\text { descriptions }\end{array}$ \\
\hline
\end{tabular}

Note. Results for mean dwell durations are presented in the appendix, Figure A2 


\section{Results}

\subsection{Quantitative findings on proportional dwell durations}

\section{RQ 1: Instructional type predicting teacher gaze for (a) student presence and (b) student engagement in problem-solving}

The Friedman test was non-significant for student presence between differences in the "introduction", "collaboration," and "reflection" parts of the teaching event. Regarding student engagement the test showed statistically significant differences $(\chi 2(2)=7, p=.03, W=0.58)$ representing a large effect (see Figure 1, top row and Table A5 in the appendix for details). Post hoc tests found significant differences between collaboration and introduction $(p=.003)$ and between collaboration and reflection $(p=.024)$.

RQ 2: Instructional type predicting teacher gaze for (a) solution paper, (b) problem-solving tools and (c) distracting objects in problem-solving

The Friedman test was found statistically significant between differences in the "introduction", "collaboration," and "reflection" parts of the teaching event for solution paper $(\chi 2(2)=6.9, p=.03, \mathrm{~W}$ $=0.57)$, problem-solving tools $(\chi 2(2)=10.2, p=.006, W=0.85)$, and distracting objects $(\chi 2(2)=10$, $p=.006, W=0.83)$, representing large effects. Again, the post-hoc tests showed significant differences when comparing the introduction and reflection periods of the teaching event against the collaboration period (see Figure 1 and Table A5 in the appendix for details).

RQ 3: Instructional types predicting teacher gaze for (a) instructional resources and (b) critical activity target

The Friedman test indicated statistically significant differences in the "introduction", "collaboration," and "reflection" parts of the teaching event for instructional resources $(\chi 2(2)=8.43, p$ $=.014, W=0.70)$, representing a large effect. Moreover, post hoc tests indicated the differences to be significant between collaboration and introduction $(p=.004)$ and between collaboration and reflection $(p<.001)$.

There were no statistically significant differences between the "introduction", "collaboration," and "reflection" parts of the teaching event for critical activity target (see Figure 1, bottom row and Table A5 in the appendix). 
Research Question 1
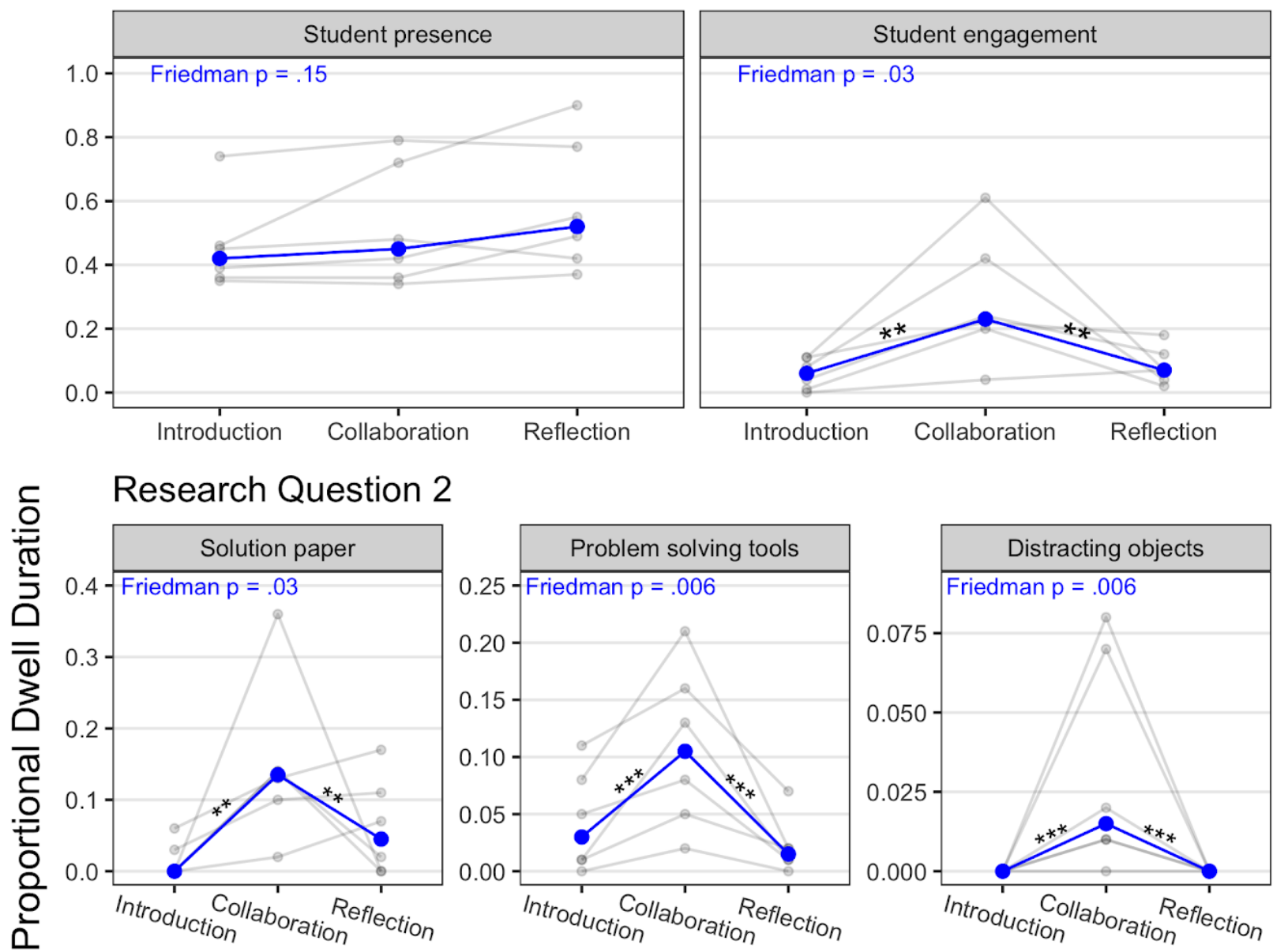

\section{Reseach Question 3}
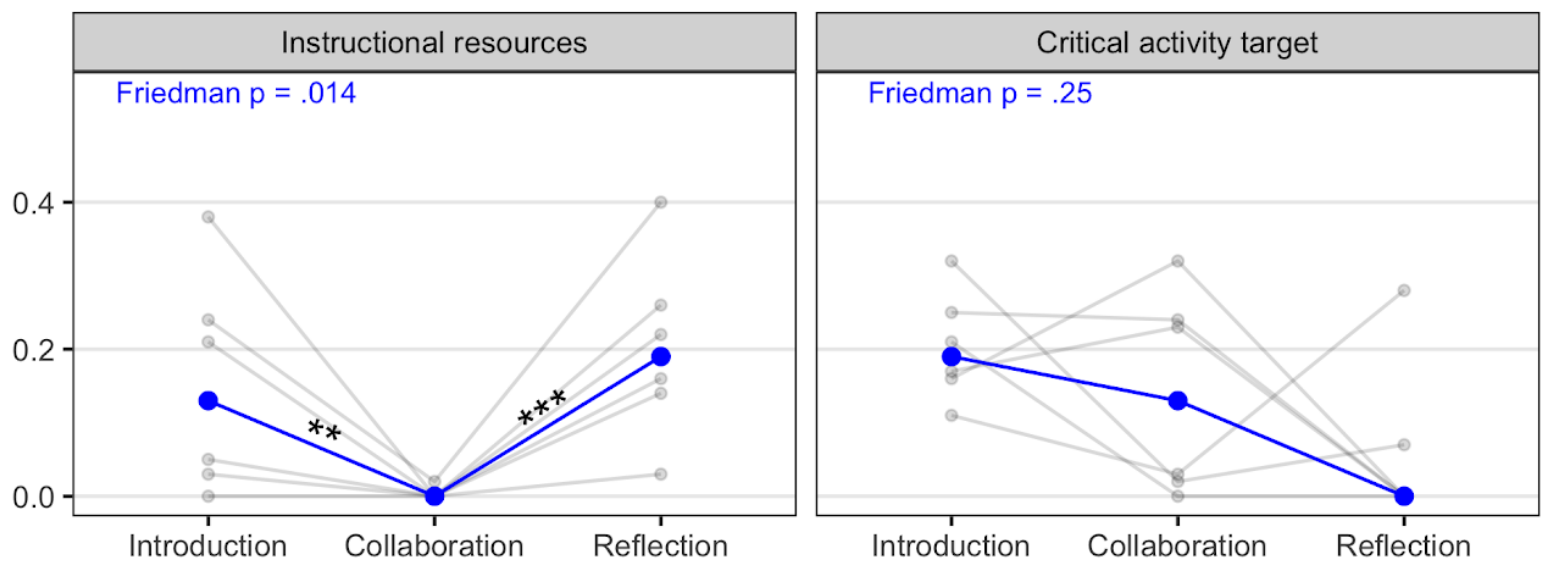

Figure 1. Results for Research Questions (RQs) 1-3 for Proportional Dwell Durations (PDDs): How do instruction types predict teacher gaze for student presence and engagement (RQ 1, top row); solution paper, problem-solving tools and distracting objects (RQ 2, middle row); instructional resources and 
critical activity target (RQ 3, bottom row)? Instruction type refers to a teacher's instruction given for introductory (individual seat-work) collaborative (pair work and group work with three to four students) and reflective (solution presentation) student work. Blue dots and lines represent the group median values, with the Friedman test p-value, when comparing the three groups, indicated at the top. The faded lines are individual observations from six teachers. $* p<.05 ; * * p<.01 ; * * *<.001$ (post-hoc tests using Conover-Nemenyi with Bonferroni-Holm corrections for multiple comparisons).

\subsection{Qualitative findings}

Next, we are using both qualitative interpretations of scanpaths and descriptions of concurrent verbalizations to shed additional light on what teachers look at when they start a new activity and how teacher speech is linked to their gaze behaviour.

\subsubsection{Overview of teachers' scanpaths}

A general notion of teachers' gaze patterns when they are introducing the problem-solving task is that teachers mostly look at student targets, mainly at student bodies and faces. Thus, when exploring the first 20 areas of interest the most common gaze target was the student, either the student's face or body except for one teacher who chose to start the lesson by projecting the task instruction on the whiteboard. That decision resulted in most teacher gazes at that specific AOI. An overview of teacher scanpaths and the percentage of dwell counts for the first 20 AOIs are shown in Figure 2.

Before suggesting more general tendencies we grouped the first 20 AOIs into four bins. At this stage, we noted that, overall, teachers looked at critical activity targets (teacher notes) first, then at student bodies and faces, followed by looks at the instructional resources (the whiteboard), and the critical activity targets (teacher desk) before they looked at another critical activity target (teacher notes) again. Thus, the teachers' gaze behaviour can be interpreted as flexible, demonstrating a readiness to respond to situational differences arising in the beginning of a lesson. The scanpaths of teachers' first 20 AOIs also show that teachers in general demonstrate their pedagogical intention in prioritizing students, embracing them around a new learning activity by maintaining eye contact with students and by placing importance at task-relevant targets.

Moreover, since gazes targeted both at the student face and student body are the most frequent in the sample for the first 20 AOIs, there seems to be a face-type and body-type gaze pattern. Distinctive for the face-type gaze pattern are consecutive gazes at the student face, whereas characteristic for the body-type gaze is that the gazes targeted at student bodies precede gazes at student faces. One explanation for the face-type gaze is the situational dynamics in the classroom. Teachers one and four are both about to start the instructions for the problem-solving task when they track restlessness, movement, and hear something that catches their visual attention. Especially, teacher one, who - after noticing the gesture of a student - calls another student by name and at the same time directs the gaze at the face of the student whose name was called. The gaze sequence then continues with repeated gazes at the student's face. Here, the successive dwells on a student's face can be more effective to restore the working conditions than the single dwells at individual students.

However, teachers one and four are experienced in classroom teaching and they seem to be aware that paying attention to students across the classroom is important. An alternative explanation for the face-type gaze is that teachers build their momentary interaction on the eye contact between them and the student. We found the scanpath of teacher five to reflect a consistency in gazing repeatedly at the student face before moving to task-relevant targets possibly suggesting shared attention. The examples demonstrate teachers' visual attention as a top-down process where their pedagogical intentions guide the gaze behaviour. 


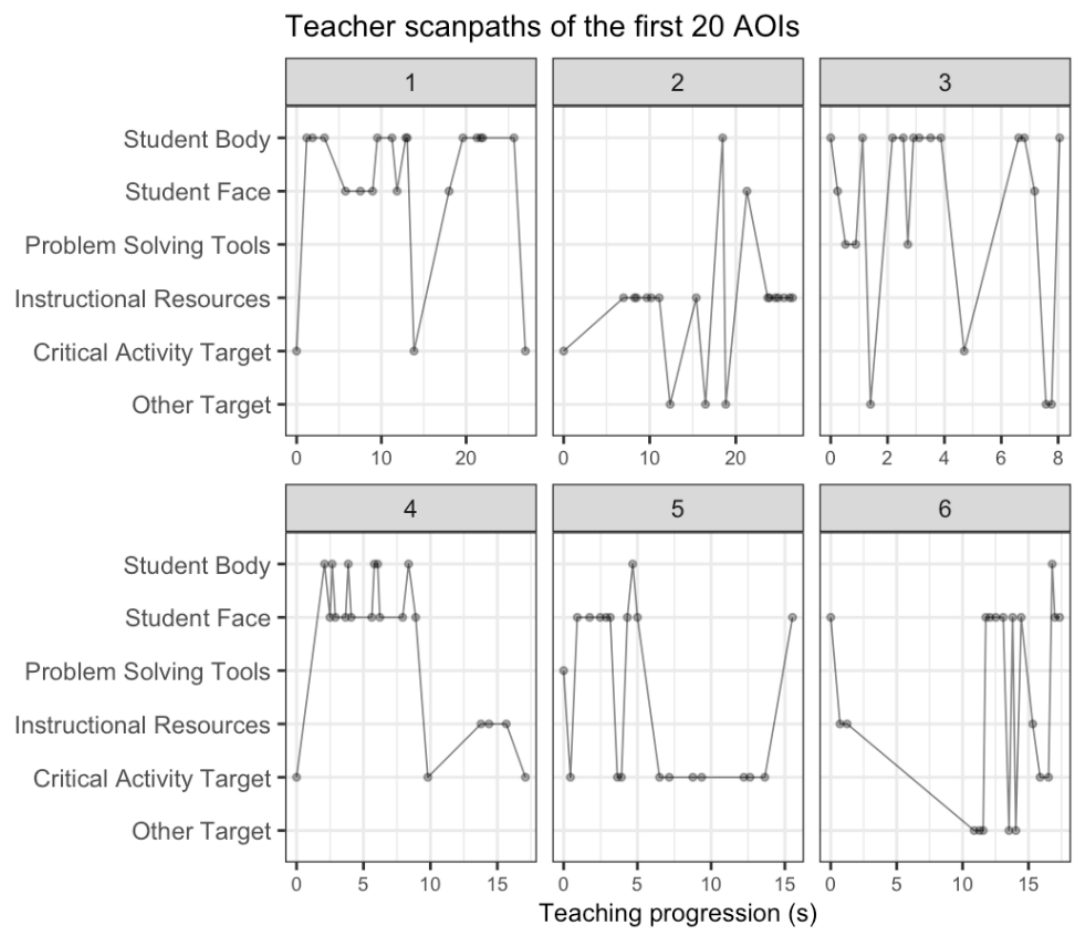

$\%$ Dwell counts across teachers

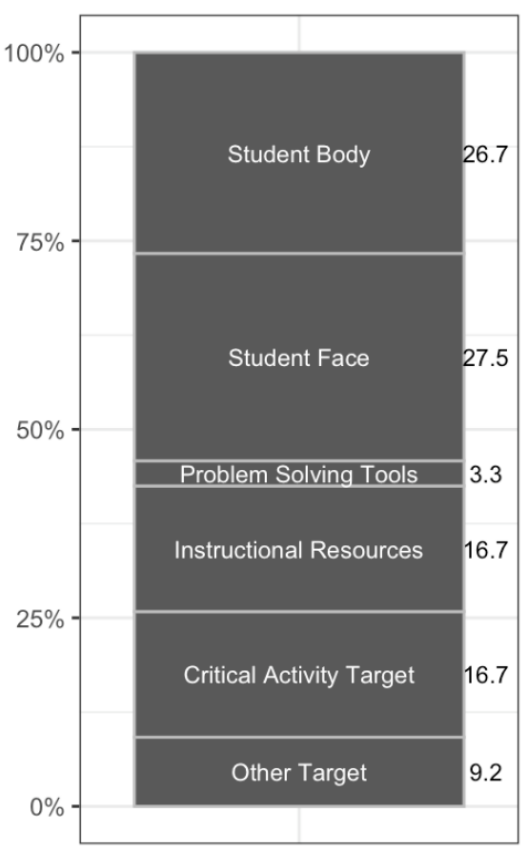

Figure 2. A. Teacher scanpaths of the first 20 AOIs and B. Proportional dwell counts across teachers during introductory task instructions.

Also, a few (between three to five) successive dwells at the same AOI (student body) exemplify the body-type gaze. There are a few possible explanations accounting for the transitions between the face-type and body-type gaze. Overall, the abundance of transitions emerged in gaze sequences when teachers introduced the problem-solving task may be a result of teachers' adaptation to the complexity of the classroom situation. Moreover, classrooms contain by default movement which is likely to bring about teacher's reflexive eye-movements. Teacher four for example uses check-ins for a student, whose hand movement is noticed resulting in a body-face-body gaze chain. Teachers with experience tend to pay attention to students' posture and bodily movements featuring bottom-up processing of gaze behavior (Wolff et al., 2016). It may be that teachers track waving or gestures and the first target AOIs are oftentimes students' hands followed by identifying the student face.

It is characteristic for teachers three and five to visually scan the classroom when starting to give the introductory instruction. Teacher three seems to distribute the visual attention across seven different AOIs when we examine the first 20 gaze targets, whereas teacher five looks at five AOIs. For teacher three the student targets gazed at represent ten different students, while teacher five only looked at four students. Interestingly, this difference cannot be explained by class size as both classes contain 19 students, neither does the duration of the excerpt favour teacher three when explaining the number of students gazed at. Still, our preliminary notions of how the gaze patterns of teachers three and five differ, concentrate on the number of gaze targets and how many individual students are looked at. One plausible interpretation is that teacher five is confident with how to cope with the situations arising, without the need to check what is going on all the time. This in turn could interestingly also be a social cue for the students, indicating that all is under control. Teachers with less classroom experience knowing neither the routines of school, the subject in depth, nor the students - would need to actively use check-ins much more often. And, vice versa, this would again be a signal to the students (together with hesitance, faltering voice etc) of less control. Considering the reasons behind the specifics of teachers' visual attention, teacher five acknowledges the power of a direct gaze when conveying the 
need to listen to the instructions. Five consecutive gazes at the student's face seem effective enough to convert an emerging disruptive incident back to focus on the task. Moreover, teacher five uses gaze to gather information on the classroom structure and its dynamics. The very first AOI in the scanpath for teacher five is a novel on a student's desk. Noticing the book at the beginning of the lesson is crucial for a later incident where teacher five spots the book again, tells the student to put the book away and instructs the student to concentrate on the problem-solving task instead. Thus, teachers' scanpaths interpreted in the context of the lesson help us to identify which decisions seem to be important and which are less important, and when they are best acted upon.

\subsubsection{Concurrent verbalizations during introductory instruction-giving}

In Figure 3 we present the scanpaths of the first five AOIs complemented with momentary descriptions of teachers' concurrent verbalizations. The onset for transcribing teacher speech was set when the teachers started to talk or signalled the start of the lesson with gestures, started to gaze at students or by using discourse markers as $u h, u m$, or hmm.

Teacher scanpaths of the first 5 AOls and verbalizations
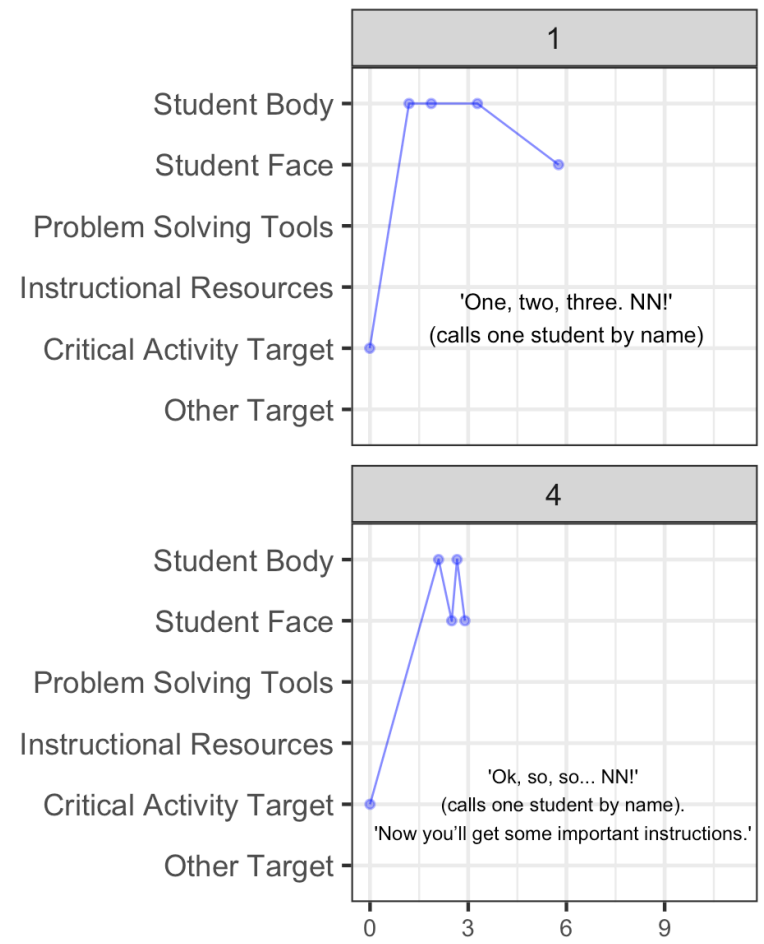
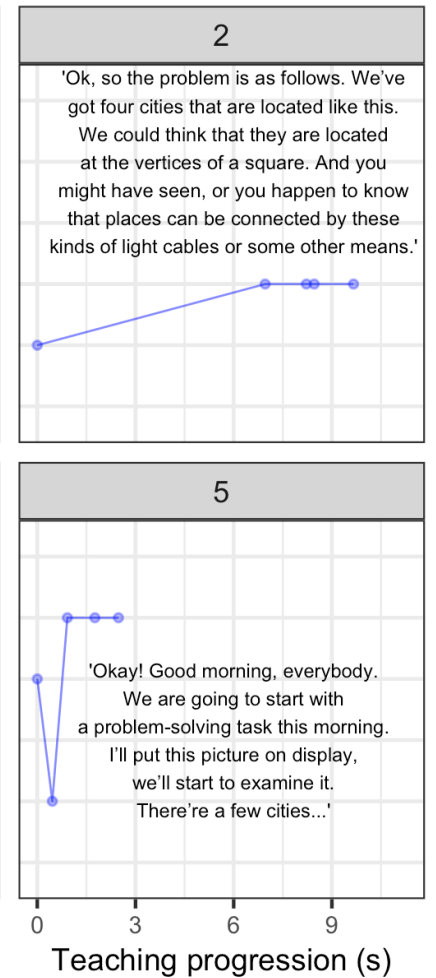

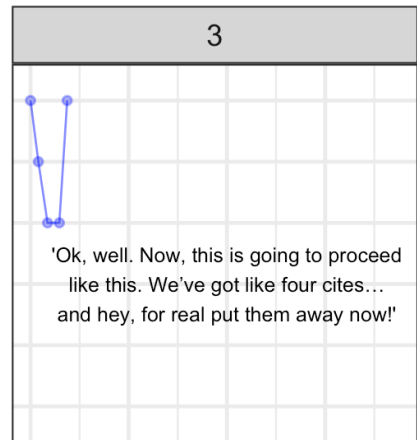

6

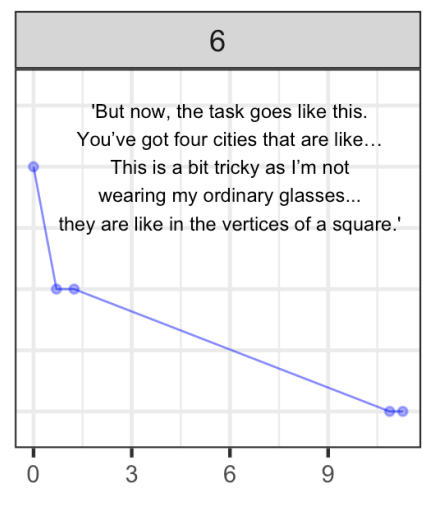

Figure 3. Teacher scanpaths of the five first AOIs and verbalizations.

In addition, the descriptions of the classroom situations for each teacher are provided as they can be seen in the video.

T1: Teacher stands next to own desk, looks at the lesson plan and counts to three while scanning the classroom. The teacher looks at the face of an inattentive student, steps toward them and says their name out loud.

T2: Teacher directs their first glance at the lesson notes under the document camera; then gazes at the ready figure on the whiteboard while illustrating cities placed in vertices of a square. 
T3: Teacher begins by standing in the front, gazing at student bodies, faces and desks. They then walk around while hesitating on how to explain the main task.

T4: Teacher stands in front of students, gazes first at the lesson plan, and then back-and-forth between one inattentive student's body and face while calling them by name.

T5: Teacher stands in front of students and looks at a student's desk and the lesson plan followed by consecutive gazes at the face of a disruptive student.

T6: Teacher stands behind the teacher's desk and looks at a student's face. The teacher turns around toward the whiteboard and marks the cities as dots in the vertices of a square. Noticing the difficulty to work without glasses, the teacher turns facing the students and draws a square in the air. At the same time, the teacher gazes at the classroom cabinets ending up with looking at the researchers in the back of the classroom.

Evidence for the contextualizing gaze and its conceptual component (a mutual goal) in the referential triangle in classroom teaching for problem-solving was particularly demonstrated by teachers one and four whose gazes were first directed at the lesson plans but then moved to student bodies and faces suggesting that teachers are actively trying to create student presence and a sense of togetherness. The two excerpts contain a typical situation in the classroom when students are involved in something else, and the teacher decides to address an individual student and demonstrates teacher presence. Also, the classroom videos indicate how teachers' postures, body orientations, and forward leans accompany teachers' gaze at students' faces together with verbalizations identifying the gaze target. Thus, disruptive behaviour gains teachers' attention.

Further, teachers two and six demonstrate gaze behaviour where the intention of the activity is conveyed by gazing at the whiteboard. Moreover, the gazing behaviour of teachers two and six highlight that teachers place importance at instructional resources when introducing a new learning activity.

Teachers three and five react differently to disruptive student behaviour and classroom situations in general when they give the introductory instructions. Teacher five tracks the restless student who is turning around in the chair, however, teacher five does not intervene verbally, but by gaze behaviour. Teacher experience may explain this notable difference. Teacher five is demonstrating a calm, and friendly atmosphere by greeting the students, explaining the task of the day by using taskrelated terminology and providing the students with hints of the lesson structure. On the contrary, teacher three starts by verbalizing the main idea of the problem-solving task using pronouns, walks around in the front of the class and ends up intervening two boys engaged in off-task behaviour.

\section{Discussion}

We examined aggregated teacher gaze measures between instructional types analysing proportional and mean dwell durations for gaze targets comprising student presence (face, body, and hands), and student engagement (solution paper, problem-solving tools, and distracting objects). Moreover, we used the same measures analysing the detailed components of student engagement, the gaze targets in instructional resources (black/whiteboard, the clock) and the targets that guide a teacher's work in the classroom which we call as critical activity targets (lesson plans).

Additionally, to identify teacher gaze patterns for the first 20 AOIs, we analysed teacher scanpaths and teachers' concurrent verbalization qualitatively. Here, we intend to identify the most frequent gaze target for each teacher and the general tendencies of what the teachers gaze at when they 
introduce a new task. Further, we are interested in how teacher scanpaths and verbal data further illuminate our research foci, teacher gaze for task readiness and task focus.

First, the current study adds to the existing process-oriented literature describing teacher behavior by tracking teacher gaze. Second, our investigations delve into the role of context in influencing teachers' gaze behaviour. Third, we have analysed the effect of instruction type on teacher gaze for detailed gaze targets suggesting a previously not detected conceptual lens for teacher intentions underlying teacher gaze.

In general, our study echoes the notions of previous research about prioritising students (McIntyre et al., 2017; Haataja, Garcia Moreno-Esteva, et al., 2019). As concluded by Haataja, Garcia Moreno-Esteva et al. (2019) teachers focus more on student faces during affective scaffolding when teacher intentions are characterized by motivating students and reducing their frustration. Our results show that teachers gaze toward students regardless of the instruction type. Thus, we were able to identify that teachers regard student presence as important during all three types of instruction-giving. Building on that, we are suggesting that teachers' pedagogical intentions in our research are first, to prepare students for a new task and second, to keep them focused and engaged in the task at hand as shown next.

Our findings also support the interpretation that teachers gaze at targets intended for student engagement (solution paper, problem-solving tools and distracting objects) result in task focus, and that the teachers thus aimed for a state of shared attention. The present study suggests that teachers should place importance at targets that are not linked to the task i.e., the distracting objects on students' desks during collaborative instruction-givings. As shown by Tomasello and Carpenter (2007), a psychological common ground of a shared goal and plans were mediated to the students by teacher gaze. Shteynberg (2015) also notes that teachers deliberately share attention with their students towards critical learning resources of the task. Hence, teacher presence re-engages students to be involved in the shared attention. Our study suggests that teachers can monitor the process of shared attention by placing importance on the solution when looking at the solution paper at the same time when instructions are given. Indeed, teachers have been reported to focus on students' solution papers during cognitive support when solving mathematical problems (Haataja, Garcia Moreno-Esteva et al., 2019). However, teachers need to be well informed of the shared-attention mechanisms as the focus of attention can easily shift from the task to the performance instead and rather impede than facilitate the problem-solving itself.

Contrary to our hypothesis, we did not notice any statistically significant differences for teacher gaze at targets indicating student presence between the three studied instruction types. Previous research on gaze duration has highlighted teachers' tendency to direct long gazes toward students they are helping (McIntyre et al., 2017). However, brief gazes in turn may either indicate expertise, and skilful teachers are able to allocate their attention between a number of students; or short glances can also reflect uncertainty or hesitation to react to what happens in the classroom (van den Bogert et al., 2014). Overall, teachers target frequent gazes at the student body in the very beginning of the lesson when a general overview of the present students is achieved. Accordingly, teachers looking at student faces - preferably engaging in eye-contact - indicates teachers' interest in individual needs of the students, as well as motivating and embracing them in the ongoing learning activity. Moreover, there is research evidence to suggest teacher expertise to be linked with more gaze at students' posture and bodily movements when viewing problematic classroom management events (Wolff et al., 2016). Also, long stares at restless students in comparison to repeated short glances at individual students and student groups serve an identical purpose noted in the current study: to make students ready for instructions for a new learning assignment. This may be an interpretation of why we did not find any statistically significant differences in the mean dwell durations nor proportions of contextualizing gaze that aims at student presence during introductory, collaborative, or reflective instruction-givings. Indeed, teachers' gaze behaviour can be explained by the innate tendency to rely on eye contact between humans (Csibra \& Gergely, 2009). It must be noted that the seating schemes in real classrooms may account for differences in the suggested face-type vs. body-type gaze. If the teacher sees the faces of the students, and the students are sitting 
facing the teacher, an eye-contact is more evident than in classrooms where the students are sitting in groups facing their peers.

Teachers seem to keep students in focus throughout the lesson. Teachers' aim is to monitor the classroom by their gaze, to create a sense of togetherness and to prepare students for the changes in the learning activities. Taken together, we incline that the teachers would be featuring a specific contextualizing gaze when introducing the task to ensure that students are listening to the instructions and understanding them. Teacher intentions behind contextualizing gaze are the same as for teachers' general didactic behaviour comprising motivation, drawing attention and raising interest toward new learning activities.

Overall, teachers' gaze behaviour reveals the essence of their intentions yielding interest in students' problem-solving tools and results, and we see teachers spending longer looking at students' solution papers, desks, and calculators when they are giving instructions for collaborative work compared with the two other instruction types. The qualitative analyses show that teachers react by their gaze behaviour to information that has instructional significance. It may be that they are able to predict more accurately the possible future events based on their representations of the classroom.

Thus, we speculate that teachers are featuring a specific collaborative gaze when instructing on the collaborative tasks to promote task focus indicated by more and longer mean dwell durations at solution papers, problem-solving tools and distracting objects. In turn, the statistically significant differences in mean dwell durations for solution paper between introductory and reflective task instruction is a research artefact; there is nothing to be found in the solution paper yet when introducing the problem-solving task. Further, the crucial phase of the problem-solving task when discussing alternate solutions, reinforcing correct answers to the problem and students motivating their answers could have yielded longer gazes at the solution paper during the reflective instruction-giving, but that was not the case.

\subsection{Limitations}

There are a number of limitations that need to be addressed for the present study. First, the small sample size ( $n=6 ; 3$ repeated measures) contributes to the limited generalizability of our findings. Despite the relatively small sample size and its contextuality, we were able to sample an interesting data set with teachers who utilized similar task instructions throughout the studied lessons. The controlled setting (the given frame for the lesson), as well as the natural settings involved (as compared with laboratory settings) add to the ecological validity. Hence, actual conclusions can be drawn for educational practice (Jarodzka et al., 2017). On the other hand, volunteer teachers may not be wholly representative, and the controlled setting probably also limits the teacher's authentic actions.

Second, there is no existing framework to entirely depict a teacher's didactic (gaze) behaviours in real-world teacher-led moments. On one hand the frameworks are created for detailed representation of the problem-solving phase (Haataja, Garcia Moreno-Esteva et al., 2019). On the other hand, they are limited to the communicative and attentional gaze (McIntyre et al., 2019). Nevertheless, our measures were designed to support the assumption that certain AOIs are detected and processed after which the interpretation drew from other data sources to triangulate the data collection. Analysing teacher scanpaths and verbalizations helped us to delineate teachers' intentions.

Third, the coding of gaze data is a lengthy process; only the first author annotated the data. However, the coding procedures were followed closely by the co-authors and miscodings were addressed consistently for all lessons before statistical analyses. Further, the detailed coding of dwells representing research specified gaze targets allowed us to aggregate teachers' gaze behaviour resulting in a model of explanatory power. While the data does not support exact statistical conclusions and such, this type of data, however, does provide valid opportunities for observing the phenomena of task readiness and task focus. 
Fourth, the categorization to introductory, collaborative, and reflective task instructions provides an appropriate basis for aggregation of data for future studies. The categorization was done to give an overview of actual teacher work in the classroom, i.e., introducing a new activity, reorganizing the social structures for collaborative activities, and reflective presentation of the results. However, it should be noted that not merging pair work and group work into a single collaborative instruction-giving would allow further analysis of how shared attention emerges in the different types of collaboration. This would certainly be an interesting future research avenue. We contend our methodological design to identify teacher intentions revealed by gaze patterns worth researching in the future.

\subsection{Implications}

Teachers may benefit from empirical evidence of how their gaze behaviour can influence their instruction. For example, how an optimal learning climate may be influenced by guiding attention to certain students, and away from others. Teachers may also guide the students' attention during lesson transitions by looking at task related targets. Sometimes attention also needs to be directed to distracting behaviour or objects, showing that they have been noticed but are not necessarily commented upon. Teachers may also aim at and enhance shared attention by gazing at e.g., student solutions.

\subsubsection{Contributions to eye-tracking research}

Our findings contribute to eye-tracking research derived from real-world classrooms and the results both underscore teachers' student-centred attention despite type of instruction and result-centred attention during collaborative instruction enabling shared attention to emerge. Consequently, an interesting topic for further work in examining teachers' gaze sequences during teacher-led moments would be controlling e.g., teacher position, class size, and students' sitting schemes.

\subsubsection{Contributions to teachers' professional development and teacher education}

New insight into teachers' gaze behaviour is meaningful for both preservice and in-service teacher training purposes. We see an opportunity to apply the results in lesson feedback sessions, part of mentoring processes and when in need of getting an overview of one-way teacher gaze behaviour. However, it is not reasonable to think that merely telling preservice or in-service teachers the fact that gazing itself at for example students would improve their professional performance. Rather, the results of our study could be applied in programs such as the one reported by Stuermer et al. (2016) where conceptual and practical knowledge are integrated into a rigorous training to describe, explain, and predict classroom situations. Moreover, didactizing the expert teacher eye-movement modeling example to be applied in teachers' professional development is certainly worth investigating (Jarodzka et al., 2017).

Hence, teachers' awareness of the top-down and bottom-up mechanisms of visual perception is important. Moreover, knowledge of the importance of gazing at students in general, and task-relevant targets in particular are critical to the success in teacher-led phases of the lesson. It is also important that teachers should strive to enable a shared attention state. That can be done by fusing the individual students into "we" when giving instructions for collaborative problem solving. Students allocate more of their cognitive capacity to those details of their environment that are thought to be co-attended with their peers (Shteynberg et al., 2014). In recent research experienced teachers have been found attempting at shared attention when focusing students' attention on important features that enhance their conceptual understanding of mathematical concepts (Pouta et al., 2020).

An implication from our study is to continue researching potential gaze sequences or patterns that appear repeatedly in time series analysis mapped into the instruction types throughout our data. Therefore, in future studies there is a call for sequence mining of extended gaze data to identify teachers' attentional patterns and thus validate additional pedagogical intentions underlying gaze.

Moreover, in the future studies we would like to break down the teachers' eye contact with students as it was apparent that teachers' gaze at students' faces did not change in accordance with the 
types of instruction-giving we were investigating. Thus, sequential analysis could be utilized to shed light on student presence which yielded non-significant differences between the types of instructiongiving. We anticipate that eye contact (gaze at student face) should differ regarding teacher gaze sequences during readiness for task and focus on task (introductory vs. collaborative instruction-giving). Creating readiness for a task would initiate with eye contact - body - eye contact gaze chains whereas focus on task would comprise repeated problem-solving tools - solution paper gaze cycles.

\section{Keypoints}

- Disentangling the effect of instruction-giving on teacher gaze, we suggest a previously not detected interpretative lens for teacher intentions.

- Teacher presence and the pedagogical intentions are manifested in the teacher's gazes at specific task-related targets.

- Two novel teacher gaze types are suggested: contextualizing gaze for students' task readiness and collaborative gaze for students' task focus.

- The results reveal teachers' student-centred attention despite instruction type and task-related attention during collaborative instruction-giving.

\section{Acknowledgments}

We would like to thank the participant teachers and students as well as Dr. Enrique Garcia Moreno-Esteva, Dr. Eeva Haataja, Dr. Anu Laine, Mrs. Jessica Salminen-Saari, Mr. Visajaani Salonen, and Dr. Miika Toivanen for their contribution in the data collection.

\section{References}

Andersen, J. F. (1979). Teacher immediacy as a predictor of teaching effectiveness. Communication Yearbook, 3, 543. https://doi.org/10.1080/23808985.1979.11923782

Anderson, N. C., Anderson, F., Kingstone, A., \& Bischof, W. F. (2015). A comparison of scanpath comparison methods. Behaviour Research Methods, 47(4), 1377-1392. https://doi.org/10.3758/s13428014-0550-3

Baron-Cohen, S. (1997). How to build a baby that can read minds: Cognitive mechanisms in mindreading. The Maladapted Mind: Classic Readings in Evolutionary Psychopathology, 207-239.

Berliner, D. C. (2004). Describing the behaviour and documenting the accomplishments of expert teachers. Bulletin of Science, Technology \& Society, 24(3), 200-212. https://doi.org/10.1177/0270467604265535

Christophel, D. M. (1990). The relationships among teacher immediacy behaviours, student motivation, and learning. Communication Education, 39(4), 323-340. https://doi.org/10.1080/03634529009378813

Cohen, P. R., \& Levesque, H. J. (1990). Intention is choice with commitment. Artificial Intelligence, 42(23), 213-261. https://doi.org/10.1016/0004-3702(90)90055-5

Cortina, K. S., Miller, K. F., McKenzie, R., \& Epstein, A. (2015). Where low and high inference data converge: Validation of CLASS assessment of mathematics instruction using mobile eye tracking with expert and novice teachers. International Journal of Science and Mathematics Education, 13(2), 389403. https://doi.org/10.1007/s10763-014-9610-5

Csibra, G., \& Gergely, G. (2009). Natural pedagogy. Trends in Cognitive Sciences, 13(4), 148-153. https://doi.org/10.1016/j.tics.2009.01.005 
ELAN (Version 5.3) [Computer software]. (2018). Nijmegen: Max Planck Institute for Psycholinguistics, The Language Archive. Retrieved from https://archive.mpi.nl/tla/elan

Ericsson, K. A., \& Simon, H. A. (1980). Verbal reports as data. Psychological Review, 87(3), 215. https://doi.org/10.1037/0033-295X.87.3.215

Farroni, T., Csibra, G., Simion, F., \& Johnson, M. H. (2002). Eye contact detection in humans from birth. Proceedings of the National Academy of Sciences, 99(14), 96029605. https://doi.org/10.1073/pnas.152159999

Foulsham, T., \& Underwood, G. (2008). What can saliency models predict about eye movements? spatial and sequential aspects of fixations during encoding and recognition. Journal of Vision, 8(2), 6. https://doi.org/10.1167/8.2.6

Frey, N., \& Fisher, D. (2010). Identifying instructional moves during guided learning. The Reading Teacher, 64(2), 84-95. https://doi.org/10.1598/RT.64.2.1

Frymier, A. B. (1994). A model of immediacy in the classroom. Communication Quarterly, 42(2), 133-144. https://doi.org/10.1080/01463379409369922

Gegenfurtner, A., Lehtinen, E., \& Säljö, R. (2011). Expertise differences in the comprehension of visualizations: A meta-analysis of eye tracking research in professional domains. Educational Psychology Review, 23(4), 523-552. https://doi.org/10.1007/s10648-011-9174-7

Gest, S. D., \& Rodkin, P. C. (2011). Teaching practices and elementary classroom peer ecologies. Journal of Applied Developmental Psychology, 32(5), 288-296. https://doi.org/10.1016/j.appdev.2011.02.004

Haataja, E., Garcia Moreno-Esteva, E., Salonen, V., Laine, A., Toivanen, M., \& Hannula, M. S. (2019). Teacher's visual attention when scaffolding collaborative mathematical problem solving. Teaching and Teacher Education, 86, 102877. https://doi.org/10.1016/j.tate.2019.102877

Haataja, E., Toivanen, M., Laine, A., \& Hannula, M. S. (2019). Teacher-student eye contact during scaffolding collaborative mathematical problem-solving. LUMAT: International Journal on Math, Science and Technology Education, 7(2), 9-26.

Hattie, J. (2003). Teachers make a difference: What is the research evidence? Paper presented at the Building Teacher Quality: What does research tell us ACER Research Conference, Melbourne, Australia. Retrieved from http://research.acer.edu.au/research_conference_2003/4/

Hendrickx, M. M., Mainhard, M. T., Boor-Klip, H. J., Cillessen, A. H., \& Brekelmans, M. (2016). Social dynamics in the classroom: Teacher support and conflict and the peer ecology. https://doi.org/10.1016/j.tate.2015.10.004

Holmqvist, K., \& Andersson, R. (2017). Eye tracking: A comprehensive guide to methods, paradigms, and measures. Lund: Eye-Tracking Research Institute.

Holmqvist, K., Nyström, M., Andersson, R., Dewhurst, R., Jarodzka, H., \& Van de Weijer, J. (2011). Eye tracking: A comprehensive guide to methods and measures. OUP Oxford.

Jarodzka, H., Holmqvist, K., \& Gruber, H. (2017). Eye tracking in educational science: Theoretical frameworks and research agendas. Journal of Eye Movement Research, 10(1):3, 1-18. https://doi.org/10.16910/jemr.10.1.3

Jennings, P. A., \& Greenberg, M. T. (2009). The prosocial classroom: Teacher social and emotional competence in relation to student and classroom outcomes. Review of Educational Research, 79(1), 491525. https://doi.org/10.3102/0034654308325693

Johnson, H. L., Coles, A., \& Clarke, D. (2017). Mathematical tasks and the student: Navigating "tensions of intentions" between designers, teachers, and students. Zdm, 49(6), 813-822. https://doi.org/10.1007/s11858-017-0894-0

Kaakinen, J. K. (2020). What can eye movements tell us about visual perception processes in classroom contexts? commentary on a special issue. Educational Psychology Review, 111. https://doi.org/10.1007/s10648-020-09573-7

Kounin, J. S. (1970). Discipline and group management in classrooms. New York: Holt, Rinehart \& Winston.

Lester Jr, F. K. (1989). The role of metacognition in mathematical problem solving: A study of two grade seven classes. Final report. 
Lukander, K., Toivanen, M., \& Puolamäki, K. (2017). Inferring intent and action from gaze in naturalistic behavior: a review. International Journal of Mobile Human Computer Interaction (IJMHCI), 9(4), 4157. https://doi.org/10.4018/IJMHCI.2017100104

Lukander, K., Toivanen, M., \& Puolamäki, K. (2017). Probabilistic approach to robust wearable gaze tracking. https://doi.org/10.16910/jemr.10.4.2

McCroskey, J. C., Richmond, V. P., Sallinen, A., Fayer, J. M., \& Barraclough, R. A. (1995). A cross-cultural and multi-behavioural analysis of the relationship between nonverbal immediacy and teacher evaluation. Communication Education, 44(4), 281-291. https://doi.org/10.1080/03634529509379019

McCluskey, R., Dwyer, J., \& Sherrod, S. (2017). Teacher immediacy and learning mathematics: Effects on students with divergent mathematical aptitudes. Investigations in Mathematics Learning, 9(4), 157-170. https://doi.org/10.1080/19477503.2016.1245047

McIntyre, N. A., \& Foulsham, T. (2018). Scanpath analysis of expertise and culture in teacher gaze in realworld classrooms. Instructional Science, 46(3), 435-455. https://doi.org/10.1007/s11251-017-9445-x

McIntyre, N. A., Jarodzka, H., \& Klassen, R. M. (2019). Capturing teacher priorities: Using real-world eyetracking to investigate expert teacher priorities across two cultures. Learning and Instruction, 60, 215224. https://doi.org/10.1016/j.learninstruc.2017.12.003

McIntyre, N. A., Mainhard, M. T., \& Klassen, R. M. (2017). Are you looking to teach? cultural, temporal and dynamic insights into expert teacher gaze. Learning and Instruction, 49, 41-53. http://dx.doi.org/10.1016/j.learninstruc.2016.12.005

McIntyre, N. A. (2016). Teach at First Sight: Expert Teacher Gaze Across Two Cultural Settings (Doctoral dissertation). University of York, York.

Mehrabian, A. (1970). A semantic space for nonverbal behaviour. Journal of Consulting and Clinical Psychology, 35(2), 248-257. https://doi.org/10.1037/h0030083

Mennie, N., Hayhoe, M., \& Sullivan, B. (2007). Look-ahead fixations: Anticipatory eye movements in natural tasks. Experimental Brain Research, 179(3), 427-442. https://doi.org/10.1007/s00221-006-0804-0

Noton, D., \& Stark, L. (1971). Scanpaths in saccadic eye movements while viewing and recognizing patterns. Vision Research, 11(9), 929-IN8. https://doi.org/10.1016/0042-6989(71)90213-6

Orquin, J. L., \& Holmqvist, K. (2018). Threats to the validity of eye-movement research in psychology. Behaviour Research Methods, 50(4), 1645-1656. https://doi.org/10.3758/s13428-017-0998-z

Polya, G. (1948). How to solve it. Princeton, NJ. Princeton University Press.

Pouta, M., Lehtinen, E., \& Palonen, T. (2020). Student teachers' and experienced teachers' professional vision of students' understanding of the rational number concept. Educational Psychology Review, 120. https://doi.org/10.1007/s10648-020-09536-y

Richmond, V. P. (1990). Communication in the classroom: Power and motivation. Communication Education, 39(3), 181-195. https://doi.org/10.1080/03634529009378801

Rothkopf, C. A., Ballard, D. H., \& Hayhoe, M. M. (2007). Task and context determine where you look. Journal of vision, 7(14), 16-16. https://doi.org/10.1167/7.14.16

Schurter, W. A. (2002). Comprehension monitoring: An aid to mathematical problem solving. Journal of Developmental Education, 26(2), 22.

Shteynberg, G. (2015). Shared attention. Perspectives on Psychological Science, 10(5), 579-590. https://doi.org/10.1177/1745691615589104

Shteynberg, G., Hirsh, J. B., Apfelbaum, E. P., Larsen, J. T., Galinsky, A. D., \& Roese, N. J. (2014). Feeling more together: Group attention intensifies emotion. Emotion (Washington, D.C.), 14(6), 1102-1114. https://doi.org/10.1037/a0037697

Simon, H. A. (1992). What is an "explanation" of behaviour? Psychological Science, 3(3), 150-161. https://doi.org/10.1111/j.1467-9280.1992.tb00017.x

Stuermer, K., Seidel, T., \& Holzberger, D. (2016). Intra-individual differences in developing professional vision: Preservice teachers' changes in the course of an innovative teacher education program. Instructional Science, 44(3), 293-309. https://doi.org/10.1007/s11251-016-9373-1

Tatler, B. W., Kirtley, C., Macdonald, R. G., Mitchell, K. M., \& Savage, S. W. (2014). The active eye: Perspectives on eye movement research. In Current trends in eye tracking research (pp. 3-16). Springer, Cham. https://doi.org/10.1007/978-3-319-02868-2 1 
Tatler, B. W., \& Land, M. F. (2016). Everyday visual attention. Handbook of Attention, 391-422.

Tomasello, M., \& Carpenter, M. (2007). Shared intentionality. Developmental Science, 10(1), 121-125. https://doi.org/10.1111/j.1467-7687.2007.00573.x

Tomasello, M., Carpenter, M., Call, J., Behne, T., \& Moll, H. (2005). Understanding and sharing intentions: The origins of cultural cognition. Behavioural and Brain Sciences, 28(5), 675-735. https://doi.org/10.1017/S0140525X05000129

Toom, A. (2006). Tacit pedagogical knowing at the core of teacher's professionality.

Van de Pol, J., Volman, M., \& Beishuizen, J. (2010). Scaffolding in teacher-student interaction: A decade of research. Educational Psychology Review, 22(3), 271-296. https://doi.org/10.1007/s10648-010-9127-6

van den Bogert, N., van Bruggen, J., Kostons, D., \& Jochems, W. (2014). First steps into understanding teachers' visual perception of classroom events. Teaching and Teacher Education, 37, 208-216. https://doi.org/10.1016/j.tate.2013.09.001

van der Want, A. C., den Brok, P., Beijaard, D., Brekelmans, M., Claessens, L. C., \& Pennings, H. J. (2015). Teachers' interpersonal role identity. Scandinavian Journal of Educational Research, 59(4), 424-442. https://doi.org/10.1080/00313831.2014.904428

Van Manen, M. (1991). Reflectivity and the pedagogical moment: The normativity of pedagogical thinking and acting. Journal of Curriculum Studies, 23(6), 507-536. https://doi.org/10.1080/0022027910230602

Van Tartwijk, J., Brekelmans, M., Wubbels, T., Fisher, D. L., \& Fraser, B. J. (1998). Students' perceptions of teacher interpersonal style: The front of the classroom as the teacher's stage. Teaching and Teacher Education, 14(6), 607-617. https://doi.org/10.1016/S0742-051X(98)00011-0

Witt, P. L., Wheeless, L. R., \& Allen, M. (2004). A meta-analytical review of the relationship between teacher immediacy and student learning. Communication Monographs, 71(2), 184-207. https://doi.org/10.1080/036452042000228054

Wolff, C. E., Jarodzka, H., van den Bogert, N., \& Boshuizen, H. P. (2016). Teacher vision: Expert and novice teachers' perception of problematic classroom management scenes. Instructional Science, 44(3), 243265. https://doi.org/10.1007/s11251-016-9367-z

Wolff, C. E., Jarodzka, H., \& Boshuizen, H. P. (2017). See and tell: Differences between expert and novice teachers' interpretations of problematic classroom management events. Teaching and Teacher Education, 66, 295-308. https://doi.org/10.1016/j.tate.2017.04.015 